\title{
Social Network Characteristics and Psychological Well-Being: A Replication and Extension
}

\author{
Barbara A. Israel, DrPH \\ Toni C. Antonucci, PhD
}

This article represents a replication and extension of a previous study by Israel and her colleagues that investigated the relationship between psychological well-being and social network characteristics. The present research included both a comparable sample of white women $(N=104)$ between the ages of 60 and 68 (as in the original study), and a more extensive adult population of men and women $(N=718)$ between the ages of 50 and 95 . The network characteristics examined are categorized along three broad dimensions: Structure-linkages in the overall network (size and density); interaction - nature of the linkages themselves (frequency, geographic dispersion, and reciprocity); and functions that networks provide (affective support and instrumental support). The results indicate a predominance of comparable findings for both the replication and extension studies. Of the eight network characteristics examined, the results of five of the regression analyses were the same across all three studies. The network characteristics of size, density, geographic dispersion, reciprocal instrumental support, and instrumental support did not make a significant contribution to the variance in psychological well-being. Of the other three network characteristics, the effect of frequency of interaction varied across the studies, and a pattern of significant results was found for affective support and reciprocal affective support. A discussion of this evidence in light of current literature and implications for practice and research is included.

We wish to acknowledge the useful comments and suggestions made on an earlier draft of this article by Jim House and the anonymous reviewers. We want to thank Myriam Torres and Halimah Hassan for their help with the data analyses, and Shirley Hatto and Sue Andersen for their assistance in preparing the manuscript.

Barbara A. Israel is with the University of Michigan, Department of Health Behavior and Health Education, School of Public Health.

Toni C. Antonucci, is with the University of Michigan, Institute for Social Research.

Reprint requests should be sent to Barbara A. Israel, Department of Health Behavior and Health Education, School of Public Health, 1420 Washington Heights, University of Michigan, Ann Arbor, MI., 48109-2029.

Health Education Quarterly,

(c) 1987 by SOPHE. Published by John Wiley \& Sons, Inc. 
The substantial growth in research investigations continues to provide evidence suggesting a positive relationship between the concepts of social networks, social support, and physical and mental health. ${ }^{1-9}$ There has been a concommitant growth in the literature that describes and evaluates the application of these findings to practice. ${ }^{10-15}$ The research evidence, however, has also been criticized for various limitations, including: Lack of agreement and specificity regarding the definition of the terms "social network" and "social support,"6,7 imprecise and inadequate measures with low reliability and validity; $;, 6,16,17$ lack of standardization of measurements making it difficult to compare findings across studies: ${ }^{18,19}$ predominant focus on social support rather than on a broader social network context $;^{7,20}$ preponderance of cross-sectional study designs; ${ }^{16,21}$ and operational confounding of independent, moderating, and dependent variables. ${ }^{3,22}$ Even given these limitations, the consistent results across a number of studies has been quite convincing.?

Some researchers have argued for the use of replication experiments in the social sciences in order to: Address unanswered questions; overcome imperfect validity; and systematically accumulate knowledge. ${ }^{23,24}$ However, such replications are rarely carried out, for various reasons including: Lack of funding, preference for testing 'new' research questions, and lack of comparable data sets. The present research is an attempt to address some of these issues and limitations within the social network and social support field through a replication and extension of an earlier study. ${ }^{25}$

The aim of the original study conducted by Israel and her colleagues ${ }^{25}$ was to examine the relationship among selected social network characteristics and psychological well-being in a nonrandom sample of 130 elderly, white women between the ages of 60 and 68 . The present investigation involves a secondary data analysis of research carried out by Kahn and Antonucci ${ }^{26}$ on social networks in adult life. The findings reported here include both a replication (examining a subsample of 104 white women between the ages of 60 and 68) and extension (using the entire nationally representative sample of 718 men and women between the ages of 50 and 95) of the initial study. The similarity of measures used in the two data sets make them especially suited for comparative analyses. (See measures section below for an in-depth discussion.)

In accordance with the original study, a social network is defined "as a specific set of linkages among a defined set of persons with the additional property that the characteristics of these linkages as a whole be used to interpret the social behavior of the person involved" 27 (p. 2). A social network is comprised of numerous characteristics along three broad dimensions: ${ }^{27,28}$ structure-links in the overall network, e.g., size and density; interaction-the nature of the linkages themselves, e.g., frequency of interaction, reciprocity, geographic dispersion; and the functions which networks provide, e.g., emotional support, tangible aid and services, access to new social ties. Therefore, a social network refers to human interactions, some or all of which may or may not provide social support.

An extensive review of the literature conducted at the time of the original study, $^{25,29}$ led to the hypotheses that each of 11 separate network characteristics is positively associated with psychological well-being, when controlling for several variables that have been found to be related to psychological well-being (e.g., marital status, income level, perceived health status). The results of the multiple regression analyses found that the only network characteristics to make a unique contribution to the variance in psychological well-being were intensity, reciprocal affective support, 
and affective support. ${ }^{25}$ The current study attempts to further clarify the relationship between network characteristics and psychological well-being in a national probability sample of noninstitutionalized adults 50-95 years of age, as well as a subsample of white women between the ages of 60 and 68 . The present study replicates the previous one by hypothesizing a positive relationship between network characteristics and psychological well-being. Specifically, each of eight network characteristics available in these secondary analyses (i.e., size, density, frequency of interaction, dispersion, reciprocal affective support, reciprocal instrumental support, affective support, and instrumental support) is hypothesized to be positively associated with psychological well-being.

\section{METHOD}

\section{Sample}

The data examined are from the study, "Social Networks in Adult Life," which was conducted in 1980 by the Survey Research Center at the University of Michigan. ${ }^{26}$ The survey respondents represented a national probability sample of 718 men and women from 50-95 years of age. In order to obtain a sufficient number of people in the older age category, all members within a sampled household 70 years of age and over were interviewed. The response rate was $73 \%$. Trained interviewers conducted in-home, structured interviews which were approximately one hour in length.

Since one of the major aims of the present research is to replicate the earlier study, a comparable subsample was drawn from this dataset that includes white women between the ages of 60 and $68(N=104)$. The examination of this subsample will be referred to as the replication study. Another aim of the present research is to investigate how the results of tests of the same hypotheses compare when using a larger, national probability sample, that includes both males and females across a broader age span. Therefore, the entire sample of 718 people (298 men and 420 women) is examined in what is referred to here as the extension study. (When both the replication and extension studies are discussed simultaneously, they will be called the present studies.) The research by Israel and her colleagues ${ }^{25}$ will be called interchangeably the original or initial study. Their sample included 130 white women between the ages of 60 and 68. This was a nonprobability sample of subjects in Durham, NC, obtained from several sources, e.g., voter registration list, retirement rosters of local businesses, and contacts made at housing units for the elderly.

\section{Measures}

The measures used in the replication and extension studies were selected based upon their similarity to the original research. A comparison of the measures across the studies for the independent, dependent, and control variables is provided in Appendix I. A description of those variables where the measures are somewhat different is presented below.

In the replication and extension studies, the respondent's personal network was delineated by presenting a figure of three concentric circles with the word "you" in 
the center. The respondent was asked to consider the three circles as including, "people who are important in your life right now," but who are not equally close. Respondents were then asked to think about "people to whom you feel so close that it is difficult to imagine life without them." The first name and last initial of such persons were entered in the innermost circle of the network diagram. Following the same procedure for the next circle, respondents were asked to indicate "people to whom you may not feel quite that close but who are still very important to you," and for the outer circle, "people whom you haven't already mentioned but who are close enough and important enough in your life that they should be placed in your personal network."

A somewhat different method was used for delineating the personal network in the original study. Using an egocentric network methodology, ${ }^{30-32}$ respondents were asked to give names of persons with whom they share various types of exchanges, e.g., help with tasks around the house; talk about personal matters; opinions considered when making important decisions: provide sick care; lend money; provide transportation; and get together to talk about hobbies or interests. The names elicited by this method were combined by the interviewer into one list of network members. The respondent was then asked to add anyone else who is important to her that did not appear on the list. From a list made up of all the people mentioned, the respondent then reviewed the names and was asked to select up to five people in descending order whom "you feel very close to now ... people you share confidences with or whom you might rely on for moral support-people you value a lot." These names made up the respondent's close network.

As is apparent, there is a difference in how the network names were elicited in these studies. Respondents in the original research delineated names of persons with whom they engaged in specific types of exchanges, and from this list selected a maximum of five closest network members. In the replication and extension studies, respondents delineated three sets of network members in descending order of closeness and importance. Since the initial study included only the closest network members, the present studies include only persons who were named as members of the inner (closest) circle of the respondent's network.

\section{Network Characteristics: Measurement Differences*}

Density. Network density in the present studies was measured by the question: "How many people in your network know one another?" The question referred to all people identified in the network diagram, not just the inner circel. The responses ranged from 1 (none of them know one another) to 5 (all of them know one another). This measure is somewhat different from the one used in the original study in which respondents were asked to indicate whether each pair of close network members knew each other well. Density of the close network was obtained by dividing the number of persons who knew each other well, by the total number of persons in the close network.

*See Appendix I for comparative description across studies of all network measures used. 
Affective Support and Reciprocal Affective Support. In reviewing the entire network diagram, respondents in the present studies indicated those persons listed on the diagram who "you confide in about things that are important to you." Affective support was measured as the number of people, averaged across the inner circle, indicated as persons with whom the respondent confides. This is somewhat different from the original study in which affective support was measured by asking for each member of the close network the question: "Would you say that you count on

for moral support often, sometimes, or rarely?" Thus, the original study assessed the frequency or amount of affective support provided by the close network member; rather than whether or not the inner circle network member provided affective support. This same differentiation applies to the reciprocal affective support measure. The original study assessed the match between the amount of moral support given and received by the respondent and close network members: whereas the present studies assessed the extent to which there was a match between who the respondent confides in and who confides in the respondent.

Instrumental Support and Reciprocal Instrument Support. Following the same procedure as described above, instrumental support in the present studies was determined using the question: "Are there people who would make sure that you are cared for if you were ill?" This was somewhat different from the original study which stated that: "Sometimes people we feel close to ask favors such as help with household tasks, transportation, for care when they are sick and so on," and asked the respondents if "In the past three months, would you say you have been helped with these kinds of things by (name of each close network member) more than five times; 3-5 times; 1-2 times; or never?" As with affective support, this is a measure of frequency of the provision of instrumental support rather than whether or not it was provided. This distinction applies to the reciprocal instrumental support measure as well.

\section{Psychological Well-Being}

The dependent variable, psychological well-being, was measured by the ten-item Affect Balance Scale (ABS) developed by Bradburn and Caplovitz. ${ }^{33,34}$ This scale assesses an individual's position on two independent dimensions-positive affect and negative affect; psychological well-being is the extent to which positive feelings outweigh negative feelings.

\section{Control Variables}

As in the orininal study, several variables were treated as controls in the present research. In the replication study, comparable measures were used to assess marital status, family income level, employment status, and perceived health status. In addi- 
tion, for the extension study, the demographic characteristics of age and sex were used as control variables.

\section{RESULTS}

As in the original study, the hypotheses were examined using regression analyses to test the independent effects of each of the network characteristics on psychological well-being, over and above any effects of the control variables. Two complete sets of analyses were carried out; the replication study involving the subsample of white women between the ages of 60 and 68 , and the extension study involving the total sample of men and women between 50 and 95 years of age. In all analyses, a hierarchical multiple regression procedure was used. The control variables were entered in the first step, followed by the specific network characteristic variable being tested, which was entered in the second step. It is important to note that the research questions of interest here are whether each of the network characteristics is a significant predictor of psychological well-being above and beyond the cumulative contribution of the control variables. Thus, these analyses are not a test of an overall regression model. Therefore, the $T$-statistic obtained in the second step of each regression analysis that tests the effect of the specific network variable in addition to the effects of the control variables is reported. Since the $R^{2}$ statistic that refers to the entire regression model is not relevant to the hypotheses being tested here, it is not presented.

As expected, in carrying out the hierarchical multiple regression analyses, the control variables cumulatively did account for a significant amount of the variance in psychological well-being for both the replication and extension studies. Table 1 presents a summary across all three studies of the contributions to psychological wellbeing of each of the network characteristics. (See Appendix II for the actual values of the statistical tests for the network characteristics in the replication and extension studies.)

\section{Structural and Interactional Network Characteristics}

In all three studies, the network characteristics of size, density, dispersion, and reciprocal instrumental support did not make a significant contribution to the variance in psychological well-being, over and above the cumulative significant effect of the control variables. Frequency of interaction did not make a unique contribution to psychological well-being in the original study or in the extension study (total sample), but did explain a significant amount of the variance in the dependent variable for the replication study, subsample of white women between the ages of 60 and $68, B=-0.557, t=2.07, p<0.05$ ). For this population, women who had more frequency of contact with inner circle network members had lower psychological well-being.

In the original study reciprocal affective support was one of the three network characteristics that were each separately found to have the hypothesized effects $(p<0.01)$. Those persons with the greater amount of reciprocal affective support had better psychological well-being. In the present investigation, reciprocal affective support was found to have similar significant results for the extension study $(B=$ 
Table 1. Summary Across Studies of Multiple Regression Analyses of Network Characteristics with Psychological Well-Being: Contributions Above and Beyond Control Variables*

\begin{tabular}{llll}
\hline $\begin{array}{c}\text { Network } \\
\text { characteristics }\end{array}$ & $\begin{array}{c}\text { Original } \\
\text { study } \\
(N=130)\end{array}$ & $\begin{array}{c}\text { Replication } \\
\text { study: } \\
\text { subsample } \\
(N=104)\end{array}$ & $\begin{array}{c}\text { Extension } \\
\text { study: } \\
\text { all cases } \\
(N=718)\end{array}$ \\
\hline $\begin{array}{l}\text { Structural } \\
\begin{array}{l}\text { Size } \\
\text { Density }\end{array}\end{array}$ & $\begin{array}{l}p=0.60 \\
p=0.89\end{array}$ & $\begin{array}{c}p=0.49 \\
p=0.51\end{array}$ & $\begin{array}{c}p=0.11 \\
p=0.64\end{array}$ \\
$\begin{array}{l}\text { Interactional } \\
\begin{array}{l}\text { Frequency of } \\
\text { interaction }\end{array}\end{array}$ & $p=0.86$ & $p=0.04$ & $p=0.49$ \\
$\begin{array}{l}\text { Dispersion } \\
\text { Reciprocal affective } \\
\text { support }\end{array}$ & $p=0.45$ & $p=0.10$ & $p=0.20$ \\
$\begin{array}{l}\text { Reciprocal instru- } \\
\text { mental support }\end{array}$ & $p=0.007$ & $p=0.78$ & $p=0.01$ \\
$\begin{array}{l}\text { Functional } \\
\text { Affective support }\end{array}$ & $p=0.23$ & $p=0.75$ & $p=0.31$ \\
$\begin{array}{l}\text { Instrumental } \\
\text { support }\end{array}$ & $p=0.01$ & $p=0.03$ & $p=0.06$ \\
\hline
\end{tabular}

*A $p$-value of $<0.05$ was considered significant for the purposes of this study.

$0.478, t=2.48, p<0.01$ ), but reciprocal affective support did not make a significant contribution in psychological well-being over and above the control variables, in the replication study.

\section{Functional Network Characteristics}

Affective support was also found in the original study to be significantly related to psychological well-being. Similar results were found in the present research. In the replication study, affective support made a unique contribution in the variance of psychological well-being over and above the cumulative effects of the control variables $(B=0.309, t=2.17, p<0.05)$. In the extension study, affective support was a predictor of the dependent variable at the $p<0.06$ level $(B=0.084, t=1.85)$. Nonsignificant results were found in all there studies for the network characteristic of instrumental support.

As in the original study, the control variables were selected based on previous empirical findings and no specific hypotheses were posited for testing. However, as in the initial study, in examining the individual contribution that each of the control variables made in explaining the dependent variable in the replication study, perceived health status explained a significant amount of the variance in psychological well-being above and beyond the other control variables $(B=0.610, t=3.01, p<0.01)$. For the extension study, of the six control variables, age $(B=0.031, t=3.39, p<0.001)$, marital status $(B=0.536, t=3.02, p<0.01)$ and perceived health status $(B=0.690$, 
$t=8.93, p<0.001)$ each made a significant contribution in the variance of psychological well-being.

\section{DISCUSSION}

In this section, the findings of both the replication and extension studies are discussed and compared with the original study. The implications of these findings in light of recent literature are considered. Structural network characteristics are discussed first, and then the Interactional Network Characteristics, and Functional Network Characteristics. The limitations of the present study are noted, followed by a brief description of practice implications and concluding comments.

\section{Structural Network Characteristics}

The same results were found for the structural network characteristics in the original research and both the replication and extension data presented here. The hypothesized relationship between each of the structural network characteristics of size and density with psychological well-being was not supported. Since the initial study was conducted, there have been numerous examinations of these structural characteristics. The somewhat contradictory findings of those studies may help to explain the present results.

On the one hand, results of some studies have found: Smaller network size to be significantly related to lower levels of psychological well-being ${ }^{35}$ network size to be a significant predictor of life satisfaction; ${ }^{36}$ total network size to be related to support satisfaction; ${ }^{37,38}$ and high levels of depressive symptoms to be inversely associated (although not reaching statistical significance) with network size. ${ }^{39}$ Other research findings, however, report that network size is unrelated to psychological distress symptomatology; ${ }^{40}$ neither the total number of supportive others or the number of people the respondent felt especially close to, were associated with psychological wellbeing: ${ }^{41}$ and in a series of life-transitions studies, network size was not related to health and well-being. ${ }^{42}$

In response to these seemingly contradictory findings, numerous authors have suggested, as did the original study, ${ }^{25}$ that the qualitative aspects of social support (e.g., satisfaction with support, perception of closeness, mutual exchange of support, how well support is provided) has greater predictive power than the quantitative characteristics of social networks, i.e., size, density, frequency of interaction. $6,39,40,43,44$ The significant results in both the replication and extension studies concerning affective support and reciprocal affective support are in agreement with this emphasis on qualitative aspects of social networks.

One possible explanation for the lack of significance of network size in the findings reported here is that only the size of the closest network members was examined (maximum of five persons in the original study, and up to ten members of the inner circle in the extension and replication studies), and not the total size of the delineated network. It may be that the positive effects of network size are only found when con- 
sidering the larger network that potentially provides multiple functions and resources, and that the benefits of a close network come from the provision of affective support (as was found here) rather than from the number of persons who comprise the close network. Several authors have argued for the need to examine extended, not just close networks, as a way of better understanding the processes that affect the relationship between social networks and health. ${ }^{20,45}$ Hence, the size of the close network may not be one of the more significant predictors of psychological well-being.

Although network density was measured somewhat differently in the original research and the present studies, the findings were nonsignificant in all three cases. Again, results from other investigations have been contradictory. For example, studies have reported: A positive relationship between density and indicators of mental health and well-being; ${ }^{46}$ a positive association between density and support satisfaction; ${ }^{38}$ a negative relationship (although denser networks provided more support) between density and support satisfaction and successful coping; ${ }^{47,48}$ and no relationship to well-being ${ }^{49}$ or support satisfaction. ${ }^{50}$ Thus, the role of network density is clearly complex, and the frequently made assumption that densely knit networks are positively related to increased support or health has not always been substantiated. $^{20}$

These varied results do tend to support the earlier arguments by Walker, et al., ${ }^{51}$ and Hamburg and Killilea, ${ }^{52}$ that smaller, dense networks, with strong ties are helpful in maintaining a positive social identity and in providing affective and instrumental support; and that larger, lower density networks are helpful during times of psychosocial transition, through the provision of new information and access to new social ties and roles. Therefore, the potential importance of network size and density may be in relation to the nature of the crisis or stress an individual is experiencing and the concommitant types of network functions needed. The lack of significant results in the present research then may be in part due to the nature of the general community sample used rather than a sample undergoing major life transitions. Additionally, Hall and Wellman ${ }^{20}$ criticize the exclusive measurement of density across the overall network, as if an individual can only be a part of a single group. Rather, they suggest that networks may be comprised of several densely knit clusters as well as more loosely knit relations and disconnected ties. Therefore, it may be that network density would be a stronger predictor of health and well-being if it were conceptualized and measured somewhat differently.

\section{Interactional Network Characteristics}

In reviewing the interactional network characteristics, examined here (Table 1), comparable nonsignificant results were found for geographic dispersion and reciprocal instrumental support. Frequency of interaction was significantly negatively related to psychological well-being for the replication study, but not for the original or extension studies. Reciprocal affective support made a significant unique contribution to psychological well-being for both the original and extension studies, but not for the replication study.

Concerning frequency of interactions, a number of studies have used indices com- 
prised of the total number and frequency of social contacts, and have shown prospectively that with broad community samples, people with few social relationships, as compared to those with moderate or high number of ties have at least twice the risk of mortality from all causes. ${ }^{6}$ Research that has specifically investigated frequency of interactions within a broader social network context have had somewhat less convincing results. One study reported that frequency of contact was unrelated to life satisfaction; ${ }^{36}$ another found that cumulative contact was not associated with personal well-being $;^{40}$ and frequency was not related to support perceptions and support satisfaction. ${ }^{38}$ Rook, ${ }^{41}$ using two different sets of frequency analyses, reported that frequent contact for purposes of socializing was related to psychological well-being, but frequency of contact with others who provided various types of social support was not associated with psychological well-being.

In none of these studies, however, was frequency negatively related to psychological well-being, as was found in the replication study presented here. One possible explanation is that among women ages 60 to 68 , those persons with more contacts also experience greater burdens that often accompany the marital and familial relationships of older women caregivers, and therefore has a negative effect on psychological wellbeing. ${ }^{53}$ This would not explain why the original comparable sample found different results. It may be that since the subjects in the original study were a nonprobability sample. that they were less representative of the general population of older women. Perhaps both the individuals themselves and the family members were healthier than in the replication study and hence they did not experience the "burden of care." More information is needed on the potentially negative aspects of relationships in order to better understand the nature of this finding. Rook, ${ }^{41}$ for example, found that psychological well-being was not significantly related to frequency of interaction with any of three groups of social network members-supporters, supportive-problematic others, and problematic others. It is apparent that the effects of frequency of contacts are not fully understood. It may be that the significance of this network characteristic is closely associated with the type of social support provided, by what source, and the accompanying need for support. Thus, persons with strong affective support needs, may benefit from frequent contact with close members of their network, but less frequent contact is necessary from other network members who might provide instrumental support.

Geographic dispersion was not found to be a significant predictor of psychological well-being in the research presented here. One possible explanation is the lack of variability of scores with these samples. In the extension study, over $80 \%$ of the inner circle network members live within an hour's drive, and in the replication study, over $75 \%$ of inner circle network members live within an hour's drive. Greater heterogeneity on this variable might have yielded different results. However, given the national representativeness of this sample, these findings reinforce earlier results that older persons are not isolated but live in close geographic proximity to important network members. 54

No other recent studies examining the relationship between psychological wellbeing and geographic dispersion were found. It may be that given past conflicting results that this network characteristic is not being considered as an important predictor of well-being. Given the relative ease and inexpensiveness of airplane travel and 
telecommunications, the geographic proximity of network members may no longer be so important.

\section{Functional Network Characteristics}

For purposes of increased conceptual clarity, the results of the functional network characteristics, affective support, and instrumental support, will be discussed in conjunction with the results of the interactional characteristics of reciprocal affective and reciprocal instrumental support. Affective support made a significant contribution to psychological well-being in both the original and replication studies and was predictive at the 0.06 level for the extension study. Reciprocal affective support was significantly related to psychological well-being for both the original and extension studies, but not for the replication study. Both instrumental support and reciprocal instrumental support were not significant across all three datasets.

The findings here concerning affective support and reciprocal affective support are consistent with results from other research. House and Kahn, ${ }^{6}$ in their review of the social support literature, state that within the different types of support, "emotional support has been most clearly linked to health, in terms of both direct effects and buffering effects," (p. 105). Goldberg and her colleagues ${ }^{39}$ found that all three measures of what they termed "quality of the subject's social network" to be strongly related to depressive symptomatology. Those persons with few confidants, with a husband who was not a confidant, or who had low levels of intimacy, were much more likely to experience high levels of depressive symptoms. Their measure of presence of confidants and the intimacy factor both included feelings of closeness and the reciprocal discussion of personal, serious problems. These factors are quite similar to the variables of affective support and reciprocal affective support as defined in the studies presented here.

The network characteristic of reciprocity, referring to the mutual exchange of network functions, has received considerable theoretical support ${ }^{55}$ and increasing empirical attention. ${ }^{56}$ In summarizing a review of the research evidence, Ingersoll-Dayton and Antonucci ${ }^{56}$ state that in contrast to relationships that are reciprocal, supportive relationships that are characterized by either excessive giving or receiving can be detrimental to well-being. In other analyses of the present dataset, ${ }^{56}$ perceived nonreciprocity accounted for a significant proportion of the variance in negative affect, but was not predictive of life satisfaction.

The similar findings presented here for affective support across all three studies, and for reciprocal affective support across two datasets, provides further evidence of the importance of these two network characteristics. It is unclear why reciprocal affective support for the replication study was not found to be significant, but here again, when compared to the extension study, it may be that the inclusion of males and younger and older adults in the latter study may help explain the observed differences. If indeed women in their 60 s are overburdened by their caregiving role, then even reciprocal relationships may not be enough to have a positive effect on psychological well-being.

Several interesting points can be made regarding the consistent finding across all 
three studies that instrumental support and reciprocal instrumental support are not significantly related to psychological well-being. Although many have argued, based on both conceptual and methodological reasons, for the importance of distinguishing among different types of network support functions, it has not been easy to obtain discriminant validity among types of support. ${ }^{6}$ It has been suggested that various types of support and their effects are most likely to be discernible "as the nature of the problem requiring support varies,"6 (p. 103). The present results would further suggest that different types of support may have separate effects. That is, while affective support was associated with psychological well-being, and instrumental support was not, instrumental support may have positive effects on some other outcome variable, such as use of health services, or may be more influential during a period of stress or crisis. Thus, our findings suggest that it is appropriate to examine both different types of support and different potential effects. The same argument could be made for reciprocal instrumental support as well. Whereas most research has investigated reciprocity in general, across types of support, the present findings suggest that the benefits of mutuality in relationships may differ by the support function provided.

\section{LIMITATIONS}

Due to the cross-sectional design, there are several limitations to the present studies. These include: The inability to discern the nature or direction of the causal relationship between social network characteristics and psychological well-being; the inability to rule out other variables, i.e. rival hypotheses that might account for the results; and the inability to take into account the dynamic nature of network characteristics and psychological well-being that occurs over the life course.

Another caveat of this research is that, although a social network approach was used, the analyses involved the closest, presumably most supportive, network members at the exclusion of more extended ties. Hence, these results relate only to close ties and do not address the potential "strength of weak ties." 57 Also, given the general community population included here, the results found may not be applicable to a clinical sample or to people experiencing a particular crisis. Furthermore, even though the extension study involved a larger, more heterogeneous sample, which enhances the generalizability of the results, we cannot rule out the possibility that differences between the replication and extension studies may be due in part to the inclusion of males and a broader age range in the latter study. It should be noted, however, that of the control variables in the extension study, age but not sex was a significant predictor of psychological well-being. (Other analyses of this dataset have explicitly examined sex and age differences. $)^{58,59}$

It is also important to recognize that there are other methodological weaknesses of the present studies and that they are not exactly comparable (e.g., differences in procedure used for delineating the social network and measures of affective support). Of course, conducting a replication study designed explicitly for such purposes would minimize these problems. It is useful to consider, however, that the few inconsistent results found here were between the replication and extension studies as well as compared to the original study, and hence methodological differences do not fully explain the different findings. 
Another critique of this type of research suggests the use of a broader network approach that goes beyond a focus on support in individualistic terms. Such an approach encourages researchers and practitioners to consider larger structural constraints that have an impact upon the provision and effects of support. ${ }^{20}$ Although the present authors agree with this critique, and have argued elsewhere for the use of a broader network analytic perspective, ${ }^{25,29}$ several advantages of using the core, close network are also recognized, e.g., it appears to have the most significant impact on health status; and it can be assessed by interview or questionnaire techniques, and can thus be measured in large scale surveys. ${ }^{6,45}$

\section{IMPLICATIONS FOR HEALTH EDUCATION PRACTICE}

Since the findings from the replication and extension studies are similar to the original study, the practice considerations for health education discussed earlier ${ }^{25,29}$ are still applicable and therefore will only be addressed briefly here. There are numerous other helpful discussions of social network interventions that examine in more depth such issues as: needs assessment, goals, strategies, evaluation, professional role, and barriers. ${ }^{10,60-64}$

Based on the results reported here, it is clear that the effects of network characteristics are complicated and variable, and hence the development of programs needs to proceed cautiously. For example, network size was not associated with psychological well-being, and therefore, it may not be effective to develop interventions primarily aimed to create new network linkages. However, if older women are overburdened by their caregiving role, then they may benefit from interventions aimed at increasing the network ties available to the persons to whom they provide care.

The somewhat consistend findings regarding the network characteristics of affective support and reciprocal affective support suggests that health education strategies, in general, be planned and implemented in a way that strengthens networks ties that are characterized by caring, intimacy, moral support, mutuality, and interdependence. Strategies that might be used to accomplish this include peer counseling and education and self-help groups. Where appropriate, such programs may need to assist participants in learning skills in how to establish and maintain relationships that involve both the provision and receipt of emotional support. Furthermore, health educators need to establish this same interdependence with persons involved in their programs. As professionals, we need to show concern for as well as recognize the expertise that lay persons have, and to develop programs that build upon and share our mutual resources.

\section{CONCLUSION}

The strengths of the present study lie not only in the results but in the replication and extension methodology used. Given the problems with the research in this area, as described earlier, it is difficult to compare findings across studies. Hence, the present study was an attempt to replicate an earlier investigation. Of the eight network characteristics examined, the results of six of the regression analyses were the same 
across all three studies. Of the two other hypothesized relationships, the findings were the same for the original study and the extension study with only the replication study having contradictory results. These consistent findings are most encouraging, and generalizability is further enhanced by the inclusion of the all cases sample of men and women between the ages of 50 and 95 , that extends beyond the original and replication sample of 60 to 68 year old women.

The pattern of significant results for the network characteristics of affective support and reciprocal affective support strongly suggest that they be further examined in future research and practice. More specifically, future research should focus on both intra and interpersonal processes in order to obtain a better understanding of the mechanisms through which affective support and reciprocal affective support influence health status. $^{43}$

Most of the structural and interactional network characteristics were not significantly related to psychological well-being. However, given the varied results from other research, it would seem that future studies should place more emphasis on, for example: Potential clustering of network characteristics with differing effects (e.g., small, dense networks that provide predominantly affective support as compared to large, loosely knit networks that provide predominantly instrumental support); the inclusion of extended ties, direct and indirect. with particular consideration of negative ties: and the examination of personal and structural determinants of network characteristics (e.g., gender differences), as a means of further clarifying why and how network characteristics affect specific outcomes.

It is apparent from this research that the relationships between network characteristics and psychological well-being are extremely complex and thus necessitate ongoing research and practice that recognizes the potential benefits, negative effects, and limitations of social networks. Since the findings presented here seem to clearly indicate that it is the provision and receipt of emotional support that are the most significant predictors of psychological well-being, we recommend that future intervention research should focus on these key factors. 


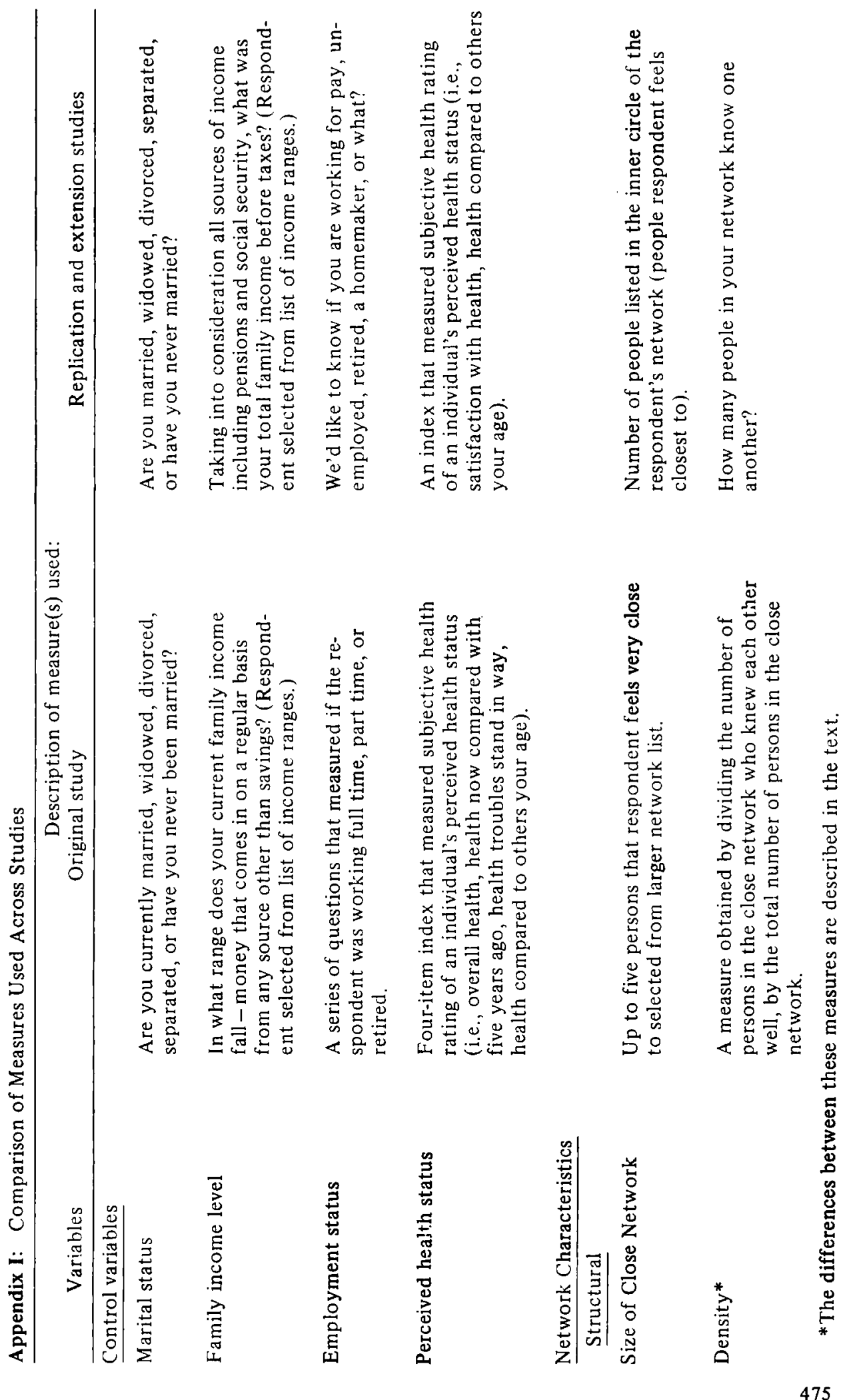




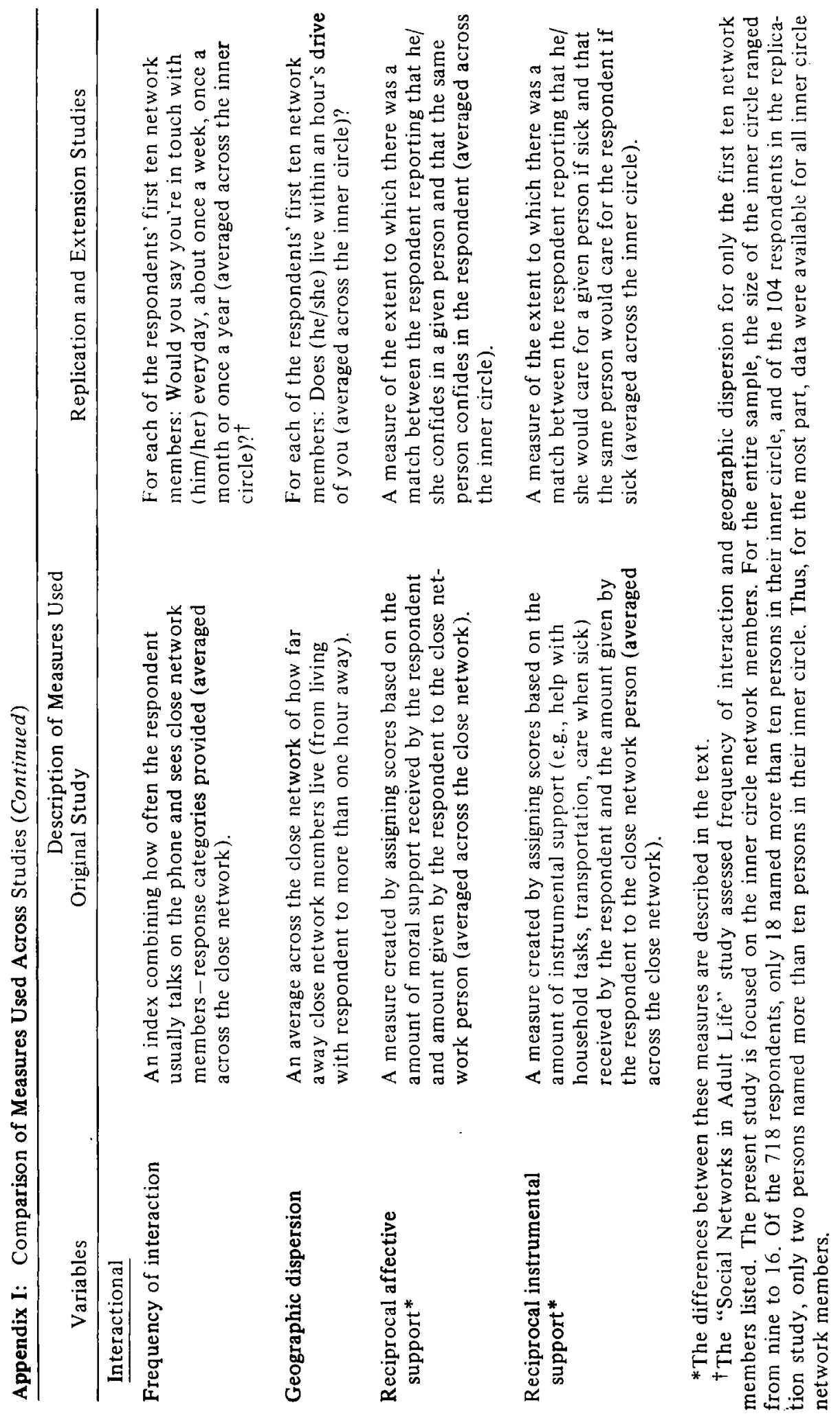




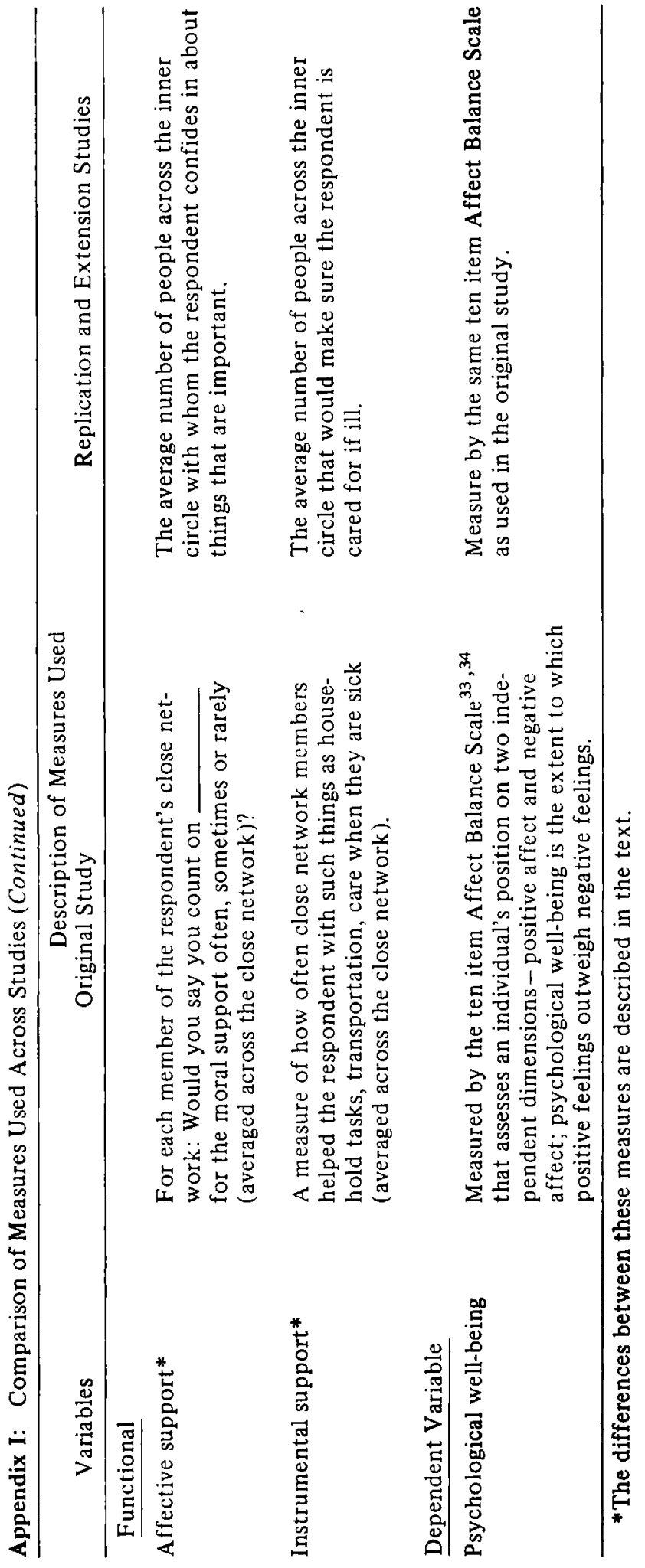


Appendix II. Nine Multiple Regression Analyses of Network Characteristics with Psychological Well-Being: Contributions Above and Beyond Control Variables for Replication and Extension Studies

\begin{tabular}{|c|c|c|c|c|c|c|}
\hline \multirow{2}{*}{$\begin{array}{c}\text { Network } \\
\text { characteristics }\end{array}$} & \multicolumn{3}{|c|}{ Replication Study $(N=104)$} & \multicolumn{3}{|c|}{ Extension Study $(N=718)$} \\
\hline & $B$ & Beta & $T$-Ratio & $B$ & Beta & $T$-Ratio \\
\hline \multicolumn{7}{|l|}{ Structural } \\
\hline Size & 0.056 & 0.069 & 0.71 & 0.047 & 0.057 & 1.59 \\
\hline Density & -0.189 & -0.063 & 0.67 & -0.046 & -0.017 & 0.47 \\
\hline \multicolumn{7}{|l|}{ Interactional } \\
\hline $\begin{array}{l}\text { Frequency of } \\
\text { interaction }\end{array}$ & -0.557 & -0.197 & $2.07 *$ & -0.074 & -0.026 & 0.70 \\
\hline Dispersion & -0.990 & -0.159 & 1.64 & -0.325 & -0.046 & 1.29 \\
\hline $\begin{array}{c}\text { Reciprocal } \\
\text { affective } \\
\text { support }\end{array}$ & 0.143 & 0.027 & 0.28 & 0.478 & 0.087 & $2.48^{\dagger}$ \\
\hline $\begin{array}{l}\text { Reciprocal } \\
\text { instrumental } \\
\text { support }\end{array}$ & 0.200 & 0.032 & 0.32 & 0.211 & 0.037 & 1.01 \\
\hline \multicolumn{7}{|l|}{ Functional } \\
\hline $\begin{array}{l}\text { Affective } \\
\text { support }\end{array}$ & 0.309 & 0.202 & $2.17^{*}$ & 0.084 & 0.065 & $1.85^{\ddagger}$ \\
\hline $\begin{array}{l}\text { Instrumental } \\
\text { support }\end{array}$ & 0.074 & 0.074 & 0.78 & 0.057 & 0.054 & 1.55 \\
\hline
\end{tabular}

\section{References}

1. Antonucci TC: Personal characteristics, social support, and social behavior, In RH Binstock, E Shanas (eds). Handbook of Aging and the Social Sciences, (2nd Edition), New York, vanNostrand Reinhold, 1985.

2. Berkman L: Assessing the physical health effects of social networks and social support, Annual Review of Public Health, 5:413-432, 1984.

3. Broadhead W, Kaplan B, James S, Wagner E, Schoenbach V, Grimson R, Heyden S, Tibblin $G$ and Gehlbach S: The epidemiologic evidence for a relationship between social support and health, Amer. J. of Epidemiology, 117:521-537, 1983.

4. Brownell A and Shumaker SA (eds): Social support: New perspectives in theory, research and intervention, Journal of Social Issues, Part I 40, 1985.

5. Cohen S and Syme L (eds): Social Support and Health, New York, Academic Press, 1985.

6. House J and Kahn R: Measures and concepts of social support, In S Cohen and L Syme (eds), Social Support and Health, New York, Academic Press, 1985.

7. Israel BA and Rounds KA: Social networks and social support: A synthesis for health educators, Advances in Health Education and Promotion, 2:311-351, 1987.

8. Sarason IG and Sarason BR (eds): Social Support: Theory, Research and Application, The Hague, Martinus Nijhof, 1985. 
8. Sarason IG and Sarason BR (eds): Social Support: Theory, Research and Application, The Hague, Martinus Nijhof, 1985.

9. Sauer W and Coward R: Social Support Networks and the Care of the Elderly: Theory, Research, Practice and Policy, New York, Springer Publishing Co., 1985.

10. Biegel DE, Shore BK and Gordon E: Building Support Networks for the Elderly: Theory and Applications, Beverly Hills, CA, Sage Publications, 1984.

11. Brownell A and Shumaker SA (Eds): Social support: New perspectives in theory, research and intervention, Journal of Social Issues, Part II 41, 1985.

12. Cwikel J and Israel BA: Examining mechanisms of social support and social networks: a review of health-related intervention studies. Submitted for review, 1987.

13. Gottlieb BH: Social Support Strategies: Guidelines for Mental Health Practice, Beverly Hills, CA, Sage Publications, 1983.

14. Israel BA and McLeroy $K$ : Social networks and social support: Implications for health education, Health Educ. Q., 12(theme issue), 1985.

15. Maguire L: Understanding Social Networks, Beverly Hills, CA, Sage Publications, 1983.

16. Cohen S and Wills TA: Stress, social support and the buffering hypothesis, Psychological Bulletin, 98:310-357, 1985.

17. Levy R: Social support and compliance: A selective review and critique of treatment integrity and outcome measurement, Social Science and Medicine, 17:1329$1338,1983$.

18. Jung J: Social support and its relation to health: A critical evaluation, Basic and Applied Social Psychology, 5:143-169, 1984.

19. Wallston B, Alagna S, DeVellis B and DeVellis R: Social support and physical health, Health Psychology, 2:367-391, 1983.

20. Hall A and Wellman B: Social networks and social support, In S Cohen, L Syme (eds), Social Support and Health, New York, Academic Press, 1985.

21. Ell K: Social networks social support and health status: A review, Social Service Review, 58:133-149, 1984.

22. Thoits P: Conceptual, methodological and theoretical problems in studying social support as a buffer against life stress, J. Health and Soc. Behav., 23: 145$159,1982$.

23. Campbell DT: Reforms as experiments, Amer. Psychol., 24:409-429, 1969.

24. Campbell DT and Fiske DW: Convergent and discriminant validation by the multitrait-multimethod matrix, Psychological Bulletin, 56:81-105, 1959.

25. Israel BA, Hogue $C C$ and Gorton A: Social networks among elderly women: Implications for health education practice, Health Educ. Q., 10: 173-203, 1983.

26. Kahn RL and Antonucci TC: Supports of the elderly: Family/friends/professionals. Final report to the National Institute on Aging, 1984.

27. Mitchell JC: The concept and use of social networks. In JC Mitchell (ed), Social Networks in Urban Situations, Analysis of Personal Relationships in Central African Towns, Manchester, England, Manchester University Press, 1969.

28. Tolsdorf CC: Social networks, support and coping: An exploratory study, Family Process, 15:407-427, 1976.

29. Israel BA: Social networks and health status: Linking theory, research, and practice, Patient Counseling and Health Education, 4:65-79, 1982.

30. Fisher CS, Jackson RM, Steuve CA, Gerson K, Jones LM and Baldassare M: Networks and Places: Social Relations in the Urban Setting. New York, Free Press, 1977.

31. Jones LM and Fischer CS: Studying egocentric networks by mass survey. Working Paper No. 384, Institute of Urban and Regional Development, University of California, Berkeley, 1978. 
32. McCallister $\mathrm{L}$ and Fischer CS: A procedure for surveying personal networks, Sociological Methods and Research, 7:131-148, 1978.

33. Bradburn NM: The Structure of Psychological Well-Being, Chicago, Aldine, 1969.

34. Bradburn NM and Caplovitz D: Reports on Happiness: A Pilot Study of Behavior Related to Mental Health, Chicago, Aldine, 1965.

35. Levitt MJ, Antonucci TC, Clark MC, Rotton J and Finley GE: Social support and well-being: Preliminary indicators based on two samples of the elderly, International Journal of Aging and Human Development, 21:61-77, 1985.

36. Heller $\mathrm{K}$ and Mansbach WE: The multifaceted nature of social support in a community sample of elderly women, J. Soc. Iss., 40:99-112, 1984.

37. Sarason IG, Levine HM, Basham RB and Sarason BR: Assessing social support: The social support questionnaire, J. Person. Soc. Psychol., 44:127-139, 1983.

38. Vaux $A$ and Harrison D: Support network characteristics associated with support satisfaction and perceived support, Amer. J. Commu. Psychol, 13:245-268, 1985.

39. Goldberg E, Van Natta $P$ and Comstock GW: Depressive symptoms, social networks and social support of elderly women, Amer. J. Epidem., 121:448-456, 1985.

40. Griffith J: Social support providers: Who are they? Where are they met? and the relationship of network characteristics to psychological distress, Basic and Applied Social Psychology, 6:41-60, 1985.

41. Rook KS: The negative side of social interaction: Impact on psychological wellbeing, J. Personal. Soc. Psychol, 46:1097-1 108, 1984.

42. Lieberman MA: The effects of social supports on response to stress. In L Goldberger, S Breznitz (eds), Handbook of Stress, New York, Free Press, 1982.

43. Antonucci TC and Jackson JS: Social support, interperstonal efficacy, and health: A life course prospective, In L Carstensen, A Edelstein (eds). Handbook of Clinical Gerontology. New York, Pergamon Press, 1987.

44. Sandler IN and Barrera $M$ : Toward a multimethod approach to assessing the effects of social support, Amer. J. Comm. Psychol., 12:37-52, 1984.

45. Hammer M: 'Core' and 'extended' social networks in relation to health and illness, Sucial Science and Medicine, 17:405-411,1983.

46. Gollo F: The effects of social support network on the health of the elderly, Social Work in Health Care, 8:65-74, 1982.

47. Hirsch B: Psychological dimensions of social networks: A multimethod analysis, Amer. J. Comm. Psychol, 7:263-277, 1979.

48. Hirsch B: Natural support systems and coping with major life changes, Amer. J. Comm. Psychol., 8:159-172, 1980.

49. Phillips SL: Network characteristics related to the well-being of normals: A comparative base, Schizophrenia Bulletin, 7:117-124, 1981.

50. Stokes J: Predicting satisfaction with social support from social network structure, American Journal of Community Psychology, 11:141-152, 1983.

51. Walker KN, MacBride A and Vachon MLS: Social support networks and the crisis of bereavement, Social Science and Medicine, 11:35-41, 1977.

52. Hamburg BA and Killilea M: Relation of social support, stress, illness and use of health services, In Healthy People: The Surgeon General's Report on Health Promotion and Disease Prevention, (Background Papers), U.S. Department of Health Education and Welfare, Public Health Service, 1979.

53. Kessler RC, MCLeod JD and Wethington E: The cost of caring: A perspective on sex differences in psychological distress, In IG Sarason and BR Sarason (eds), Social Support: Theory, Research and Applications, The Hague, Martinus Nijhof, 1985. 
54. Shanas E: The family as a social support system in old age, The Gerontologist, 19:169-174, 1979.

55. Shumaker SA and Brownell A: Toward a theory of social support, J. Soc. Iss., 40:11-36, 1984.

56. Ingersoll-Dayton B and Antonucci TC: Nonreciprocal social support: Another side of intimate relationships. Under review.

57. Granovetter M: The strength of weak ties, Amer. J. Soc., 78:1360-1380, 1973.

58. Antonucci TC and Akiyama $\mathrm{H}$ : An examination of sex differences in social support in mid- and late-life, Sex Roles, In press.

59. Antonucci TC and Akiyama $\mathrm{H}$ : Social networks in adult life and a preliminary examination of the convoy model, Journal of Gerontology. Accepted for publication.

60. Chapman NJ and Pancoast DL: Working with informal helping networks of the elderly: The experiences of three programs, J. Soc. Iss., 41:47-63, 1985.

61. Israel BA: Social networks and social support: Implications for natural helper and community level interventions, Health Educ. Q., 12:65-80, 1985.

62. Froland C, Pancoast DL, Chapman NJ and Kimboko PJ: Helping Networks and Human Services, Beverly Hills, CA, Sage Publications, 1981.

63. Gottlieb BH: Social Support Strategies: Guidelines for Mental Health Practice. Beverly Hills, CA, Sage Publications, 1983.

64. Israel BA: Community-based social network interventions: Meeting the needs of the elderly, Danish Medical Bulletin, Special Supplement Series on Gerontology, Forthcoming. 